\title{
Systems Chronobiology: Global Analysis of Gene Regulation in a 24-Hour Periodic World
}

\author{
Jérôme Mermet, Jake Yeung, and Felix Naef \\ Institute of Bioengineering, School of Life Sciences, Ecole Polytechnique Fédérale de Lausanne, \\ $\mathrm{CH}-1015$ Lausanne, Switzerland \\ Correspondence: felix.naef@epfl.ch
}

\begin{abstract}
Mammals have evolved an internal timing system, the circadian clock, which synchronizes physiology and behavior to the daily light and dark cycles of the Earth. The master clock, located in the suprachiasmatic nucleus (SCN) of the brain, takes fluctuating light input from the retina and synchronizes other tissues to the same internal rhythm. The molecular clocks that drive these circadian rhythms are ticking in nearly all cells in the body. Efforts in systems chronobiology are now being directed at understanding, on a comprehensive scale, how the circadian clock controls different layers of gene regulation to provide robust timing cues at the cellular and tissue level. In this review, we introduce some basic concepts underlying periodicity of gene regulation, and then highlight recent genome-wide investigations on the propagation of rhythms across multiple regulatory layers in mammals, all the way from chromatin conformation to protein accumulation.
\end{abstract}

\section{TEMPORAL GENE REGULATION THROUGH THE LENS OF THE CIRCADIAN CLOCK}

Circadian rhythms in behavior and physiology are widespread across living organisms ranging from cyanobacteria to humans (BellPedersen et al. 2005). Unlike other temporally ordered processes, such as embryonic development or response to acute stimuli, gene regulation considered over a normal day recurs with a well-defined period of 24 hours (Doherty and Kay 2010). These periodic patterns depend on the interactions between environmental cycles and endogenously ticking clocks (Partch et al. 2014). In mammals, these biological clocks consist of a network of hierarchical oscillators in which the master clock, located in the suprachi- asmatic nucleus (SCN), controls rhythms in behavior (Mohawk and Takahashi 2011) and coordinates physiological rhythms across peripheral organs through systemic signals such as hormones and temperature rhythms (Mohawk et al. 2012). Natural light cycling in the environment constitutes the main "clockdriver," or Zeitgeber, and synchronizes the central clock in the SCN with the environment. Nevertheless, other Zeitgebers, such as temperature fluctuations and feeding rhythms, contribute to the entrainment of clocks in tissues outside of the SCN (Damiola et al. 2000; Stokkan et al. 2001). To decipher how deep the circadian rhythms are encoded within the organism, single-cell analyses have shown that circadian oscillations rely on a cell-autonomous

Editors: Paolo Sassone-Corsi, Michael W. Young, and Akhilesh B. Reddy

Additional Perspectives on Circadian Rhythms available at www.cshperspectives.org

Copyright (C) 2017 Cold Spring Harbor Laboratory Press; all rights reserved; doi: 10.1101/cshperspect.a028720

Cite this article as Cold Spring Harb Perspect Biol 2017;9:a028720 
J. Mermet et al.
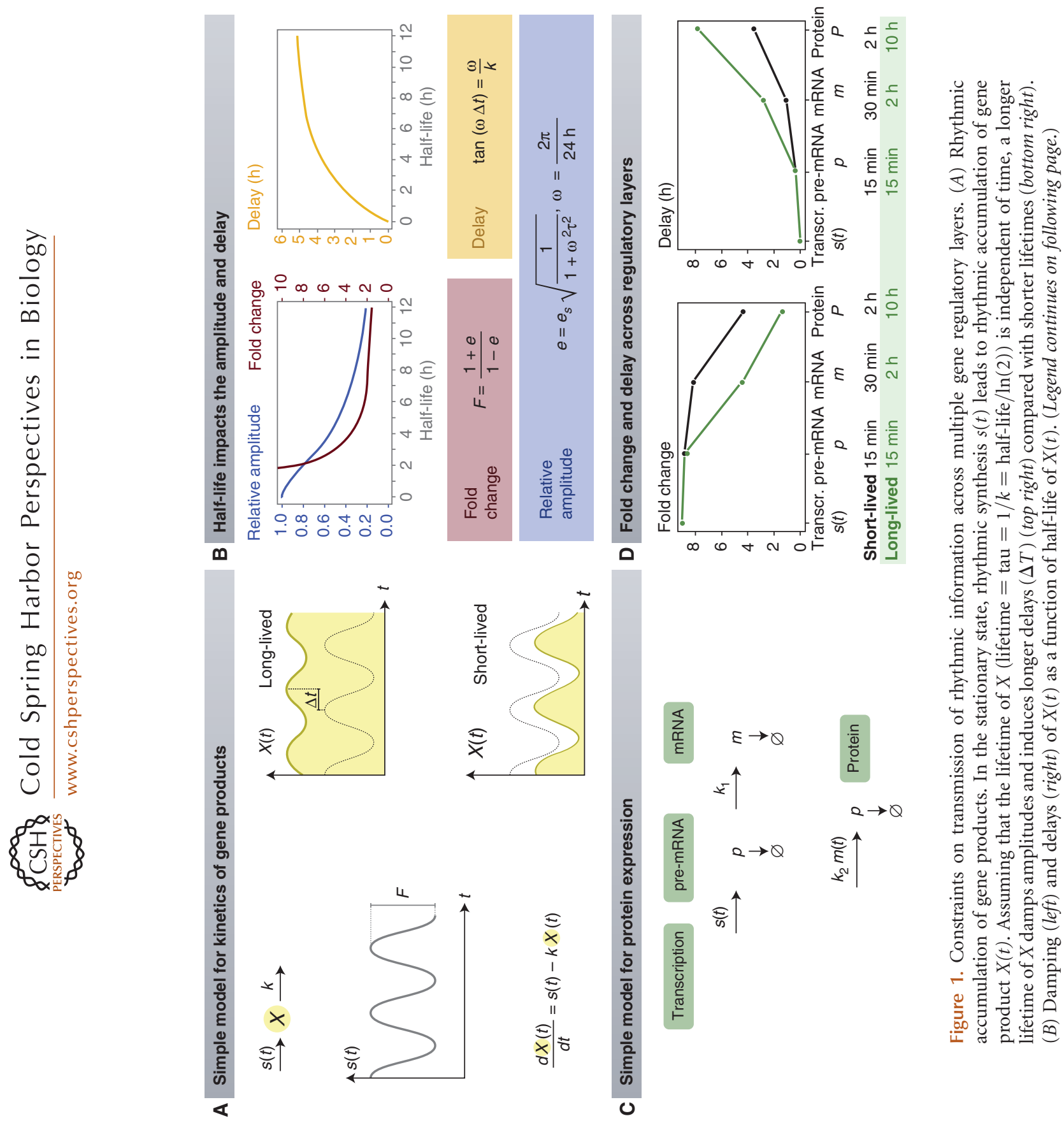
process, suggesting that potentially every cell in an organism can resonate with environmental time (Nagoshi et al. 2004; Welsh et al. 2004).

Thus, a major challenge in systems chronobiology is to unravel how the clock synchronizes physiology across distinct organs, and in particular how the clock modulates the different layers of gene regulation. In this review, we first refresh concepts underlying how rhythmic information is transmitted across each gene regulatory layer. Next, we highlight recent systems approaches that extend our understanding of circadian gene regulation, all the way from chromatin conformation to translation and protein accumulation.

\section{CONSTRAINTS ON TRANSMISSION OF RHYTHMIC INFORMATION ACROSS MULTIPLE REGULATORY LAYERS OF GENE EXPRESSION}

To start with a natural and simple scenario, let us consider a product $X$ synthesized according to a rhythmic synthesis function $s(t)$, with a mean and relative amplitude, and is then transformed or degraded at a temporally fixed rate $k$ (Fig. 1A). From this model, the relative amplitude of $X$ is damped and its rhythm delayed compared with the source $s$ (Fig. 1A). A longer lifetime (large $1 / k$ ) relative to the circadian period increases this damping and the delay (Figs. 1A,B). For example, a half-life of 2 hours for a protein (such as DBP, a protein with robust oscillations) (Fonjallaz et al. 1996) is accompanied by a reduction in relative amplitude by a factor of 0.8 compared with the originating mRNA. Moreover, this damping is accompanied with a delay of 2.5 hours (Fig. 1B).

A basic model of protein expression that involves several of such steps sequentially, from transcription to translation, would predict damping and delays that depend on the halflives of all gene products (Fig. 1C,D). Indeed, amplitude damping and phase delays have been observed as rhythms propagate from transcription to mRNA as well as from mRNA to protein (Le Martelot et al. 2012; Mauvoisin et al. 2014). These simple models illustrate that, without further regulation, it is in principle more difficult to transmit rhythmic information that is encoded at the transcriptional level compared with protein degradation or protein localization. However, additional active regulations relieve constraints on damping and delays. For example, half-lives that are rhythmic, rather than constant, allow phases to shift arbitrarily and boost relative amplitudes (Luck et al. 2014). Half-lives were reported to vary in circadian genes through mechanisms including mRNAbinding proteins, alternative splicing (Preussner et al. 2014), RNA methylation (Fustin et al. 2013), and phosphorylation of proteins (Vanselow et al. 2006; Mehra et al. 2009; Zhou et al. 2015). Overall, the circadian system represents an attractive model to study the dynamics of gene regulation at every layer from transcription to translation.

\section{STATISTICAL METHODS FOR THE IDENTIFICATION OF PERIODIC GENE EXPRESSION PATTERNS}

In this section, we discuss the main methods that are commonly applied to identify temporal patterns in periodic gene expression. The problem of identifying periodic signals has a long history (Fisher 1929; Hartley 1949). In the context of circadian "omics" experiments, it has been mostly tackled as a univariate problem, in which each gene in the data set is tested for

Figure 1. (Continued) With increasing half-life, relative amplitudes (or fold change) are damped and $X(t)$ is delayed up to a maximum of 6 hours. Tau $=1 / k ; e_{s}=$ relative amplitude of synthesis. $(C)$ Simple model for protein expression. Transcription $s(t)$ produces pre-mRNA $(p)$, which can be processed into mature mRNA $(m)$. Proteins are synthesized at a rate proportional to the accumulation of mRNA. In the simplest model, the half-life of each gene product is assumed to be independent of time. (D) Damping (left) and delays (right) of rhythms in short-lived versus long-lived mRNAs and proteins. Gene products with shorter half-lives preserve rhythmic information more efficiently than those with longer half-lives. Initial fold change of $s(t)$ was chosen as 9 to illustrate damping of amplitude. 
periodic expression independently. To account for testing multiple genes, this procedure is usually followed by a correction for multiple testing (Noble 2009). Because this problem has been extensively discussed (Wijnen et al. 2005; Luck and Westermark 2016), we will not be exhaustive but will only illustrate the main ideas. Methods can be broadly classified as parametric and nonparametric. A common parametric method is harmonic regression, in which a sine wave is fitted to the data assuming Gaussian noise, which leads to F-statistics (Fisher 1929). One way to handle periodic signals that deviate from sinusoids is to allow for higher harmonics, coupled with model selection (Costa et al. 2013). Overall, the methods based on linear transformation are simple and can be extended to handle more complex situations, such as comparisons across multiple conditions. However, caution must be taken when periodic signals deviate from sinusoids and when the noise in gene expression is far from Gaussian, such as in counts data encountered in RNA-sequencing data sets (Love et al. 2014).

Nonparametric methods may be better suited when the periodic patterns deviate from sinusoids or when there are outliers. One approach uses the ranks of the data points to analyze how the data increases and decreases over time. JTK_CYCLE compares the rank of values against an underlying sinusoidal waveform (Hughes et al. 2010). RAIN builds on the strengths of JTK_CYCLE and expands the method to detect nonsymmetrical waveforms, where the increasing and decreasing segments may be unrelated (Thaben and Westermark 2014). Nonparametric methods handle nonstandard rhythmic patterns but could be more difficult to extend to accommodate comparisons across multiple conditions.

On the other hand, the comparison of rhythmic patterns across different conditions (e.g., across tissues, genotypes, feeding conditions) has been less studied. Although many comparative studies have intersected lists of rhythmic genes based on cutoffs, this approach is often unsatisfactory because of its dependence on arbitrary cutoffs. A more refined approach is to ask whether two or more patterns are rhythmic with the same amplitude and phase. Within the framework of linear regression, the Chow test can be used for two conditions and a model selection approach can be used for three or more conditions (Chow 1960; Atger et al. 2015). Finally, we note that, with some exceptions (Leng et al. 2015; Hughey et al. 2016), the problem has been tackled gene by gene. Multivariate approaches that leverage rhythmic or mean signals across multiple genes may provide additional insights toward the regulation of gene modules across conditions.

In the remaining sections, we discuss recent advances toward obtaining a comprehensive view of circadian gene expression programs, and the mechanisms by which certain molecular machineries resonate with diurnal fluctuations.

\section{MODEL OF THE MAMMALIAN CORE CLOCK}

At the cellular level, molecular oscillators encode circadian rhythms (Bell-Pedersen et al. 2005). In mammals, although the nature of the molecular pacemaker is still not resolved (Edgar et al. 2012), it is assumed that transcriptional-translational feedback loops (TTFLs) play an important role (Partch et al. 2014; Robinson and Reddy 2014). In the current TTFL model, the CLOCK-BMAL1 transcription factor heterodimer binds E-box DNA sequence and drives the expression of Period (Per1, Per2, and Per3) and Cryptochrome (Cry1 and Cry2) genes. In turn, PER and CRY proteins negatively regulate CLOCK-BMAL1 trans-activation effect and repress their own transcription (Gekakis et al. 1998; Sangoram et al. 1998; Kume et al. 1999; Zheng et al. 1999). A second loop consists of the transcriptional control of the nuclear-receptors $\operatorname{Rev}-\operatorname{Erb} \alpha / \beta$ and $\operatorname{Ror} \alpha / \beta / \gamma$ by the CLOCK-BMAL1 complex (Everett and Lazar 2014). By competitive binding to RORE-responsive-elements (RREs) on the DNA, REVERB and ROR proteins, respectively, repress or activate Bmall gene transcription (Preitner et al. 2002; Akashi and Takumi 2005; Guillaumond et al. 2005; Takeda et al. 2012). 


\section{TRANSCRIPTIONAL REGULATION OF CLOCK CONTROLLED GENES}

Core clock transcription factors regulate clockcontrolled output genes such as the PAR bZIP transcription factors, TEF, HLF, and DBP, which bind D-boxes' DNA sequences in the genome and regulate target gene expression (Gachon et al. 2006; Stratmann et al. 2012). Interestingly, the PAR bZIP transcription factors oscillate with high amplitudes in the liver but with low amplitudes in most brain regions (Gachon et al. 2004). In mammals, a large number of transcripts show circadian accumulation, many of which are tissue specific (Panda et al. 2002; Storch et al. 2002; Zhang et al. 2014). The core clock machinery can generate tissue-specific circadian transcriptomes indirectly by activating tissue-specific transcription factors in a rhythmic manner or directly by cooperating with tissue-specific transcription factors to output rhythmic gene expression in a specific tissue (Andrews et al. 2010; Korencic et al. 2014; Zhang et al. 2015).

The mouse liver, because of its cellular homogeneity and the large amount of biological material obtainable, has been extensively studied at the genome-wide level. Around 10\%$15 \%$ of genes in the liver were described as rhythmically transcribed (Hughes et al. 2009; Vollmers et al. 2009), although this figure depends entirely on the applied criteria, such as cutoffs or the set of genes considered. For example, diurnal rhythms in gene expression were shown to represent $\sim 50 \%$ of the liver transcriptome (Mauvoisin et al. 2014). However, even in the liver, the number of cyclic mRNAs with large amplitudes (e.g., larger than twofold) remains relatively low (Kornmann et al. 2007). This fluctuating transcription is in part the consequence of temporal changes in the recruitment of core clock transcription factors themselves to the chromatin, as well as rhythmic RNA polymerase II (RNA pol II) loading (Cho et al. 2012; Koike et al. 2012; Le Martelot et al. 2012). For example, BMAL1 binds to $>2000$ sites in the genome including genes implicated in carbohydrate and lipid metabolism (Rey et al. 2011). Histone modifications and chromatin remodeling, which are signatures of gene activity (Bernstein et al. 2007), are also rhythmic around the clock.

Indeed, many studies reported histone modifiers and remodelers as part of the clockwork machinery, such as the histone acetyltransferase (HAT) p300 (Etchegaray et al. 2003), the histone methyltransferases MLL1 (Katada and Sassone-Corsi 2010), and MLL3 (Valekunja et al. 2013). The CLOCK protein itself was reported to show HAT activity (Doi et al. 2006). BMAL1 was recently described as a pioneer transcription factor capable of opening the chromatin (Menet et al. 2014). This is particularly interesting because rhythmic chromatin remodeling and time varying nucleosome occupancy were previously observed (Ripperger and Schibler 2006). On the other hand, biochemical analyses led to the identification of transcriptional repressors associated with core clock components such as the nucleosome remodeling and deacetylases (NuRD) complex (Kim et al. 2014), the nuclear receptor corepressor (NCoR) (Yin and Lazar 2005), Polycomb group proteins (Etchegaray et al. 2006), and histone deacetylases (Feng et al. 2011).

An interesting property of the clockwork machinery resides in its capability to sense the cellular environment through coregulators. In mouse liver, SIRT1, an $\mathrm{NAD}^{+}$-dependent HDAC, inhibits BMAL1-CLOCK activity (Nakahata et al. 2008). Moreover, CLOCK-BMAL1 activates the transcription of the rate-limiting enzyme, NAMPT, which is involved in $\mathrm{NAD}^{+}$ biosynthesis (Ramsey et al. 2009), ultimately resulting in SIRT1 activation and BMAL1CLOCK inhibition. This mechanism uses metabolites to integrate energy status of the cell with the circadian clock (Berger and SassoneCorsi 2015).

Although a more detailed understanding of circadian regulation of transcription is emerging, many aspects remain unclear. For example, how does the circadian clock associate with tissue-specific components as well as signals to transcribe the proper genetic repertoire at the right moment in the right organ and, in fine, optimize circadian physiological function? This question has been the purpose of a recent review 
series (Hussain and Pan 2015). Also, the roles of histone variants (Menet et al. 2014) and distal regulatory sequences in controlling circadian transcription are still understudied and challenging. For example, a large fraction of BMAL1 binding sites (60\%) is located $>10 \mathrm{~kb}$ away from the nearest TSS (Rey et al. 2011), raising questions about whether these distal sites are enhancers. Interestingly, recent RNAsequencing experiments revealed the presence of thousands of circadian enhancer-RNAs (eRNAs) in mouse liver (Fang et al. 2014). As is often performed in similar studies in other fields, candidate enhancers are assigned to target promoters according to genomic proximity; however, physical distance (measured in 3D) would be functionally more relevant. In the next section, we discuss recent work exploring chromatin conformation, both in general and in the context of circadian biology.

\section{RHYTHMIC TRANSCRIPTION IN A THREE- DIMENSIONAL NUCLEUS}

Our current understanding of the global spatial organization of the mammalian genome has benefitted from two main experimental approaches. First, chromosome conformationcapture assays, or " $\mathrm{C}$ "-based techniques, which evaluate the frequency of cross-links between genomic regions (de Wit and de Laat 2012). Among the " $\mathrm{C}$ " techniques, $3 \mathrm{C}$ reveals contact frequencies between few selected pairs of genomic fragments (Dekker et al. 2002), 4C between one locus (the bait) and the entire genome (Simonis et al. 2006), 5C between many and many loci (Dostie et al. 2006), and Hi-C monitors interactions between pairs of genomic sites genome-wide (Lieberman-Aiden et al. 2009). Moreover, ChIA-PET can identify chromatin hubs bound by a given protein (Fullwood et al. 2009). Thus, owing to the biochemical methods involved, "C" techniques usually provide information on chromatin conformation averaged over millions of cells. Second, fluorescence in-situ hybridization (FISH) uses microscopy to directly measure physical distances between genomic loci in individual cells, but with a lim- ited throughput on the number of pairs (Fraser et al. 2015).

The emerging picture can be recapitulated as a hierarchical compartmentalization of the mammalian genome (Bickmore and van Steensel 2013; Dekker and Heard 2015). Briefly, individual chromosomes occupy discrete territories in the nucleus (Cremer and Cremer 2001) and gene rich chromosomes tend to be located near the center of the nucleus. Inside chromosome territories, different chromatin compartments segregate according to chromatin states (Lieberman-Aiden et al. 2009). Recently, Hi-C experiments revealed that mammalian genome folds into structures called topologically associating domains (TADs) (Dixon et al. 2012). TADs are $100-\mathrm{kb}$ to $1-\mathrm{Mb}$ scale chromatin domains that appear to be conserved between mammals (Dixon et al. 2012; Vietri Rudan et al. 2015). Moreover, CTCF and cohesin protein complexes appear to play a major role in governing the contours of chromatin folds, such as TAD boundaries and enhancer-promoter contacts (Dixon et al. 2012; Seitan et al. 2013; Rao et al. 2014; Zuin et al. 2014; Vietri Rudan et al. 2015). Importantly, functional interactions between genomic loci, such as promoter-enhancer pairs, mainly occur within a genomic scale typical of TADs, that is, dozens to hundreds of kilobases, and can be cell-typespecific (Hughes et al. 2014; Mifsud et al. 2015; Schoenfelder et al. 2015). Recently, elegant experiments using CRISPR-Cas9 genome engineering tools showed that chromatin contacts can be rearranged and transcription perturbed by removing CTCF sites or TAD boundaries (Guo et al. 2015; Tsujimura et al. 2015). So far, the best examples that explore chromatin conformation and their functional significance for processes such as transcription have come from developmental biology. The locus control region (LCR) controlling the transcription of $\beta$-globin genes directly contacts target promoters in specific tissues and developmental stages (Tolhuis et al. 2002; Chang et al. 2013; Deng et al. 2014; Bartman et al. 2016). Also, Hox genes and chromatin domains orchestrate folding rearrangements and switches in transcriptional states (Chambeyron and Bickmore 2004; Noor- 
dermeer et al. 2011, 2014). Altogether, these studies illustrate the tight connections between chromatin folding and gene expression.

As previously mentioned, the circadian oscillator offers a unique model to study periodic transcriptional regulation. The circadian system is also an ideal system to explore temporal dynamics in the spatial organization of the genome and associated function on gene regulation. Does the global folding of the genome oscillate in a circadian manner? Do circadian genes cluster together? Do regulatory sequences rhythmically contact circadian gene promoters? So far, only a few studies have addressed these questions. The first one used chromosome conformation capture on chip (4C) in wild-type and clock-deficient mouse embryonic fibroblasts (MEFs) to evaluate chromatin contacts involving the $D b p$ promoter (Aguilar-Arnal et al. 2013). Interestingly, although most genomic contacts remained globally stable, there were also circadian fluctuations and clock-dependent chromatin interactions connecting $D b p$ promoter. These rhythmically contacting regions included circadian genes and genomic elements such as E-boxes, which were supported by DNA-FISH (Aguilar-Arnal et al. 2013). However, this study focused exclusively on interactions with regions on trans-chromosomes. A more recent study took advantage of pairedend sequencing of $4 \mathrm{C}$ libraries to reconstruct networks surrounding the H19 imprinting locus in human ES cells (Zhao et al. 2015). First, the investigators found the locus Pard 3 among the contacted hubs in human embryonic stem (ES) cells. Then in human HCT116 cells, in which Pard 3 was expressed in a circadian manner, the locus was rhythmically recruited to the nuclear lamina, a well-known repressive compartment of the nucleus (Kind et al. 2015). Interestingly, this recruitment was dependent on CTCF and PARP1 protein functions, the latter having been previously linked to the clockwork machinery in the mouse liver (Asher et al. 2010). Moreover, the rhythmic recruitment of Pard3 to the lamina was corroborated with 3D DNA-FISH experiments and appeared essential for its oscillating transcription (Zhao et al. 2015). To correlate chromatin structure with gene expression, $\mathrm{Hi}-\mathrm{C}$ and $3 \mathrm{D}$ imaging were compared with RNA-Seq around the clock, which showed correlations between chromatin folding and transcription dynamics for certain genes involved in the cell cycle and circadian rhythms (Chen et al. 2015). In this study, comparing the structure and function of the genome suggested correlation between physically interacting gene pairs. For example, 3D DNA-FISH showed that distances between Per2 and Clock rhythmically fluctuate over the day; the two genes were close together when mRNA accumulation of Per2 was low and Clock was high (Chen et al. 2015). Overall, these studies suggest a link between circadian transcription and dynamics of chromatin folding (Fig. 2B). Future investigations combining ChIP-sequencing for factors such as CTCF and cohesin subunits with highresolution chromosome conformation capture assays and genome editing would help to further establish functional relationships between chromatin folding and the molecular clocks. Interestingly, recent findings suggested a role for CTCF and cohesin in insulating phases of circadianly expressed genes, probably through their function in delimiting TAD, as well as via a functional role of cohesin in connecting gene promoters to distal regulatory elements (Xu et al. 2016).

So far, we have discussed circadian fluctuations in transcription, with an emphasis on the potential role of three-dimensional conformations of the chromatin. However, only a limited overlap was found between the rhythmic accumulation of pre-mRNA and that of mature mRNA (Koike et al. 2012; Menet et al. 2012), suggesting a role of posttranscriptional mechanisms in circadian gene regulation. In the next section, we discuss recent advances in the understanding of posttranscriptional regulation in circadian biology.

\section{CIRCADIAN POSTTRANSCRIPTIONAL REGULATION AT THE RNA LEVEL}

With constant half-lives of gene products, amplitudes damp and the phase is delayed (Fig. 1). However, additional regulations, such as the rhythmic degradation of intermediate prod- 


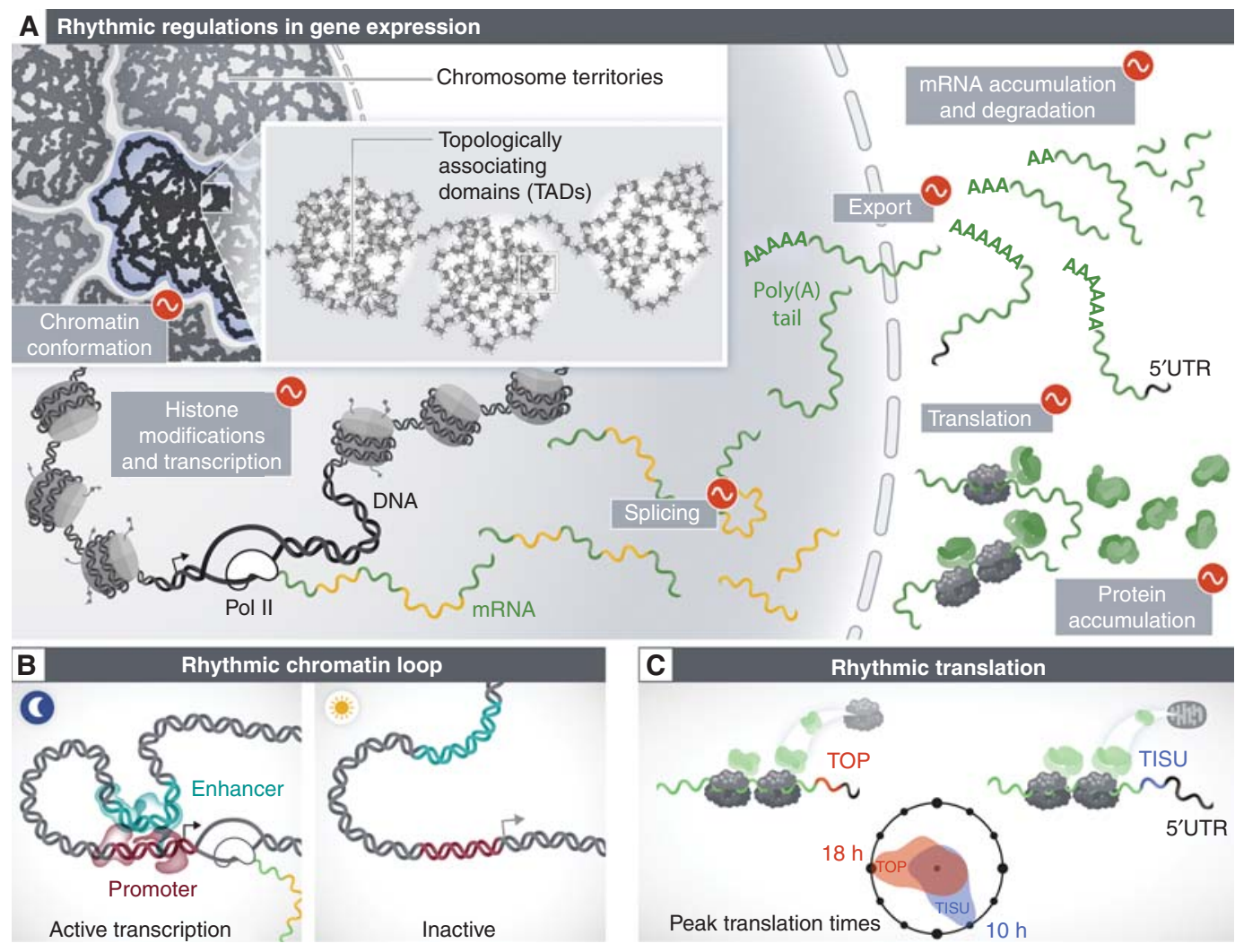

Figure 2. Circadian regulation of gene expression. (A) Circadian rhythms can impact gene expression at virtually any step between transcription to translation. In mammals, although many steps of gene regulation such as transcription, mRNA, and protein accumulation are known to fluctuate over the day, the role of the clock in other steps such as splicing and mRNA transport is less understood. Recent advances have highlighted other levels of regulation involving the circadian clock, such as chromatin structure and translation. (B) Recent advances highlighted the role of chromatin conformation in regulating circadian genes. For instance, rhythmic contacts between distal genomic regulatory sequences and gene promoters contribute to circadian gene expression. $(C)$ By measuring translation rate around the clock, ribosome-profiling experiments found that translation efficiency fluctuates over the diurnal cycle. Thus, although TOP and TISU motif mRNAs accumulate constantly in mouse liver, the rhythmic translation rate of these mRNAs allows fluctuating protein synthesis encoding ribosomal (TOP) and mitochondrial (TISU) functions.

ucts, can further modulate gene expression, for example, by tuning the amplitude or shifting the phase of the driving rhythm (Le Martelot et al. 2012; Luck et al. 2014). One straightforward way to identify transcriptional and posttranscriptional regulatory events underlying circadian gene expression is to compare measures of transcription, mRNA accumulation, translation efficiency, and protein accumulation. Recently, many studies used different techniques to analyze transcriptional activity and
mRNA accumulation in mouse liver around the clock. For example, the process of transcription was measured by quantifying nascent RNA chains that are associated with the chromatin (Menet et al. 2012). Others have compared RNA Pol II loading in gene bodies as a proxy for transcription with mRNA accumulation using microarrays (Le Martelot et al. 2012). Furthermore, total RNA-Seq is assumed to simultaneously estimate transcriptional activity (intronic reads) and accumulation of mature 
mRNAs (exonic reads) (Koike et al. 2012; Du et al. 2014; Atger et al. 2015; Gaidatzis et al. 2015).

Although studies have identified notable genes regulated at the posttranscriptional level, such as Tfrc (Janich et al. 2015) and Cirbp (Morf et al. 2012), the genome-wide extent of posttranscriptional regulation of the circadian transcriptome varies from different studies (Koike et al. 2012; Le Martelot et al. 2012; Menet et al. 2012). This divergence is likely a result of different experimental and analysis methods used (Luck et al. 2014). A recent meta-analysis and data modeling approach considered production and degradation rates as circadian parameters, and concluded that $30 \%$ of circadian genes are regulated posttranscriptionally (Luck et al. 2014).

Altogether, genome-wide approaches measuring transcription, RNA processing, and accumulation, as well as single-gene studies, emphasized that a non-negligible amount of circadian genes are subjected to posttranscriptional regulation (Kojima et al. 2011; Beckwith and Yanovsky 2014). For example, perturbation of RNA methylation leads to a longer circadian period phenotype in both human and murine cells (Fustin et al. 2013). An important mechanism of RNA processing that greatly expands the diversity of transcripts is alternative splicing (Nilsen and Graveley 2010). Although this process could, in principle, regulate circadian accumulation of many transcripts, surprisingly few works have analyzed the contribution of alternative splicing to mammalian circadian gene expression. In fact, exon arrays have shown that relatively few circadian transcripts $(0.4 \%)$ are regulated at the splicing level in mouse liver (McGlincy et al. 2012), although these transcripts included notable clock components such as Clock and Npas2. Single-gene analysis reported that rhythmic degradation of PER1 is regulated by circadian alternative splicing of the U2AF26 factor (Preussner et al. 2014). In cultured mouse cells, the temperature entrainment of the clock was shown to involve posttranscriptional mechanisms. Notably, the cold-inducible RNA-binding protein (CIRBP) is involved in temperature entrainment of the clock, possibly by binding to transcripts encoding circadian oscillator proteins, such as clock (Morf et al. 2012). Interestingly, CIRBP and RBM3, another RNA-binding protein, dictate the choice of polyadenylation sites of target transcripts in a circadian manner (Liu et al. 2013).

Circadian rhythms in poly(A) tail lengths have been known for a long time (Robinson et al. 1988). Using comprehensive methods, hundreds of transcripts showed a circadian poly (A) tail length in mouse liver, some of which correlated with circadian transcription as well as protein abundance (Kojima et al. 2012). Thus, rhythmic deadenylation of transcripts could affect circadian transcripts half-life and translation efficiency. Nocturnin (NOCT) is a cytoplasmic deadenylase rhythmically expressed and controlled by the clock. Furthermore, NOCT KO mice showed resistance to diet-induced obesity (Green et al. 2007; Li et al. 2008). Therefore, it may be tempting to speculate that NOCT could regulate the global circadian fluctuations in the length of poly $(\mathrm{A})$ tails of mRNAs, but recent mouse mutant studies have not confirmed this hypothesis (Kojima et al. 2015). Interestingly, NOCT itself is posttranscriptionally regulated by the microRNA (miRNA) miR-122 (Kojima et al. 2010). miR122 is important for hepatic circadian functions and targets genes involved in cholesterol and lipid metabolism (Gatfield et al. 2009). Using an inducible DICER knockout, an elegant study evaluated the global contribution of miRNAs to circadian gene expression in mouse liver ( $\mathrm{Du}$ et al. 2014). Although a non-negligible fraction of circadian transcripts was affected by miRNAs, this study emphasized the resilience of the circadian clock to perturbations in miRNA biogenesis ( $\mathrm{Du}$ et al. 2014). Taken together, these results underscore the importance of posttranscriptional regulation of molecular clocks. However, the underlying mechanisms are still not well understood and further efforts are needed to better appreciate the usage of different strategies controlling circadian gene expression at multiple steps. In the next section, we discuss recent works highlighting the role of translation in circadian biology using ribosome profiling and quantitative mass-spectrometry. 
J. Mermet et al.

\section{CIRCADIAN REGULATION IN TRANSLATION EFFICIENCY}

The process of translating mRNA into protein is tightly regulated but its contribution to circadian biology remains poorly studied. A few reports have indicated that RNA-binding proteins such as LARK and heterogeneous nuclear ribonucleoprotein (hnRNP) complexes are implicated in circadian modulation of translation in mammals (Kojima et al. 2007; Kim et al. 2010; Lee et al. 2012). The first study to assess translation efficiency globally used microarrays of polyribosome occupancy in mouse liver around the clock (Jouffe et al. 2013). Interestingly, this work revealed that the expression of translation factors such as initiation factors, ribosomal proteins, and ribosomal RNAs underlie circadian regulation. Moreover, the rhythmic expression of ribosome biogenesis intermediates and translation initiation factors were impaired in clock-deficient mice (Jouffe et al. 2013). This link between the circadian clock, ribosome synthesis, and translation initiation raises the question of whether translation rate itself can be rhythmic. To comprehensively address this, ribosome profiling, which consists of measuring ribosomal occupancy on transcripts, is the method of choice. Translation efficiency is estimated by comparing ribosomal occupancy to transcript abundance. This approach was applied to human cell line (Jang et al. 2015) and mouse liver around the clock (Atger et al. 2015; Janich et al. 2015). The results suggested that, for most genes, when transcription fluctuates in a circadian manner, mRNA accumulation and protein synthesis follows. Nevertheless, the three studies found a few exceptions. Protein synthesis can be rhythmic from mRNAs whose abundances are constant. Conversely, mRNA abundance can be rhythmic but lead to flat ribosomal occupancy (Atger et al. 2015; Jang et al. 2015; Janich et al. 2015). For example, iron metabolism mRNAs accumulate constantly but are rhythmically translated in mouse liver (Janich et al. 2015). Because ribosome-profiling studies detect only relative effects on translation rate of individual transcripts, quantifying the absolute ribosome occupancy requires internal controls such as RNA spike-ins (Lian et al. 2016).

A remarkable observation in mouse liver and human cells is the presence of upstream open reading frame (uORFs) in core clock mRNAs (Jang et al. 2015; Janich et al. 2015). Although the functions of the short peptides translated from these uORFs are unknown, disruption of translation reinitiation perturbed the circadian period length of mouse fibroblast (Janich et al. 2015). The most complete investigation on translation efficiency included clock-deficient animals and different feeding regimen (Atger et al. 2015). Interestingly, gene sets encompassing TOP and TISU motifs in the 5'UTRs were rhythmically translated but had constant mRNA abundance (Fig. 2C). These gene sets were associated with ribosomal function, reinforcing previous observations that circadian rhythms are integrated with translation machinery (Jouffe et al. 2013). Importantly, comparing clock wild type with BMAL1 mutant suggested that feeding, rather than the clock, is the main driver of rhythmic translation in the liver (Atger et al. 2015). This is intriguing because the BMAL1 protein itself was linked to translation function (Lipton et al. 2015). Indeed, in MEFs, mass spectrometry of components precipitating with BMAL1 revealed the presence of proteins related to translation. BMAL1 was associated with translation initiation factors in the cytoplasm and promoted cap-dependent translation initiation. Furthermore, the role of BMAL1 in translation was linked to the mTOR pathway (Lipton et al. 2015).

Altogether, these findings suggest that translation is an integral part of the clockwork machinery. The dynamics of protein accumulation throughout the day is discussed in the next section.

\section{CIRCADIAN RHYTHMS IN PROTEIN ACCUMULATION}

The first studies evaluating temporal changes in protein accumulation used 2D-gel electrophoresis performed over the clock. This technique revealed that proteins in mouse liver and other 
organs accumulated in a circadian manner (Reddy et al. 2006; Podobed et al. 2014). Interestingly, the identified proteins were involved in key physiological functions such as sugar metabolism in liver. More recently, stable isotope labeling of amino acids (SILAC) followed by mass spectrometry enabled quantitative analysis of the circadian proteome. This approach quantified the relative abundances of an unprecedented number of proteins in the SCN (Chiang et al. 2014) and liver (Mauvoisin et al. 2014; Robles et al. 2014) of mice. Overall, $5 \%$ to $10 \%$ of the detected proteins accumulated in a circadian manner, encoding essential biological processes such as mitochondrial oxidative phosphorylation in the SCN (Chiang et al. 2014), detoxification (Robles et al. 2014), and protein secretion in mouse liver (Mauvoisin et al. 2014). A remarkable observation in mouse liver is that virtually all secreted proteins accumulate rhythmically with a peak at Zeitgeber Time 18 but are encoded by flat mRNAs. This emphasizes the possible relevance of the circadian rhythms in controlling systemic signals. Comparing the proteomes of liver in wildtype versus clock-deficient mice suggested that feeding was the main driver of rhythmic protein accumulation (Mauvoisin et al. 2014). Notably, about half of rhythmic proteins did not come from rhythmic mRNAs, suggesting active circadian translation or rhythmic degradation. Interestingly, for the other half, the amplitudes of rhythmic proteins were damped and phases were shifted by an average of $5.5 \mathrm{~h}$. Simple kinetic models incorporating protein half-life data predicted a delay of $6 \mathrm{~h}$ and damped of amplitudes (Fig. 1C), suggesting that the reduced protein amplitudes likely originated from long protein half-lives.

Taken together, these proteomics data, despite relatively low sensitivity compared with DNA and RNA-sequencing approaches, suggested that proteins accumulate rhythmically over the day and in a tissue-specific manner. These results were complemented by absolute quantifications of copy number for core clockproteins over the circadian cycle in mouse liver (Narumi et al. 2016). Future studies investigating the circadian dynamics of the distribution of proteins across different cellular subcompartments might be more informative. Interestingly, recent findings suggest that mitochondria also show circadian proteome content mediated by the PERIOD complex (Neufeld-Cohen et al. 2016). Finally, critical posttranslational mechanisms such as protein folding, transport, and biochemical modifications are not discussed here.

\section{PERSPECTIVES IN SYSTEMS CHRONOBIOLOGY}

In this review, we discussed recent advances coming from large-scale molecular explorations of the mammalian circadian clock. Because the circadian system provides a unique dynamic context, it represents an exciting model for exploring functional genomics. Over the last decade, temporal analyses of gene regulation emphasized a vast and continuous regulatory landscape underlying the mammalian molecular clocks. This includes transcription, RNAprocessing, and translation to mention only the most obvious.

However, important questions in circadian biology remain. The building of a comprehensive map of chromatin organization, alternative splicing, RNA transport, protein turnover, and posttranslational modifications around the clock remains exciting challenges. Furthermore, most studies on circadian biology have focused on populations of cells. Recent advances in single-cell technologies will reveal new aspects of circadian gene regulation, such as cell-to-cell variability in chromosome conformation, transcription, and mRNA accumulation (Suter et al. 2011; Nagano et al. 2013; Achim et al. 2015; Battich et al. 2015). New large-scale approaches coupled with computational modeling will be needed to tackle these critical challenges.

\section{ACKNOWLEDGMENTS}

We thank Eric Paquet and Jingkui Wang for critical reading and informative discussions. We thank Laura Symul for illustrations and discussions. This work was supported by Swiss National Science Foundation Grant 31003A- 
153340 and European Research Council Grant ERC-2010-StG-260667, and by the Ecole Polytechnique de Lausanne. J.Y. benefits from the Natural Sciences and Engineering Research Council of Canada Postgraduate Studies Doctoral scholarship.

\section{REFERENCES}

Achim K, Pettit JB, Saraiva LR, Gavriouchkina D, Larsson T, Arendt D, Marioni JC. 2015. High-throughput spatial mapping of single-cell RNA-seq data to tissue of origin. Nat Biotechnol 33: 503-509.

Aguilar-Arnal L, Hakim O, Patel VR, Baldi P, Hager GL, Sassone-Corsi P. 2013. Cycles in spatial and temporal chromosomal organization driven by the circadian clock. Nat Struct Mol Biol 20: 1206-1213.

Akashi M, Takumi T. 2005. The orphan nuclear receptor $\mathrm{ROR} \alpha$ regulates circadian transcription of the mammalian core-clock Bmal1. Nat Struct Mol Biol 12: 441-448.

Andrews JL, Zhang X, McCarthy JJ, McDearmon EL, Hornberger TA, Russell B, Campbell KS, Arbogast S, Reid MB, Walker JR, et al. 2010. CLOCK and BMAL1 regulate $M y o D$ and are necessary for maintenance of skeletal muscle phenotype and function. Proc Natl Acad Sci 107: 19090-19095.

Asher G, Reinke H, Altmeyer M, Gutierrez-Arcelus M, Hottiger MO, Schibler U. 2010. Poly(ADP-ribose) polymerase 1 participates in the phase entrainment of circadian clocks to feeding. Cell 142: 943-953.

Atger F, Gobet C, Marquis J, Martin E, Wang J, Weger B, Lefebvre G, Descombes P, Naef F, Gachon F. 2015. Circadian and feeding rhythms differentially affect rhythmic mRNA transcription and translation in mouse liver. Proc Natl Acad Sci 112: E6579-6588.

Bartman CR, Hsu SC, Hsiung CC, Raj A, Blobel GA. 2016. Enhancer regulation of transcriptional bursting parameters revealed by forced chromatin looping. Mol Cell 62: 237-247.

Battich N, Stoeger T, Pelkmans L. 2015. Control of transcript variability in single mammalian cells. Cell 163: 15961610.

Beckwith EJ, Yanovsky MJ. 2014. Circadian regulation of gene expression: At the crossroads of transcriptional and post-transcriptional regulatory networks. Curr Opin Genet Dev 27: 35-42.

Bell-Pedersen D, Cassone VM, Earnest DJ, Golden SS, Hardin PE, Thomas TL, Zoran MJ. 2005. Circadian rhythms from multiple oscillators: Lessons from diverse organisms. Nat Rev Genet 6: 544-556.

Berger SL, Sassone-Corsi P. 2015. Metabolic signaling to chromatin. Cold Spring Harb Perspect Biol 8: a019463.

Bernstein BE, Meissner A, Lander ES. 2007. The mammalian epigenome. Cell 128: 669-681.

Bickmore WA, van Steensel B. 2013. Genome architecture: Domain organization of interphase chromosomes. Cell 152: $1270-1284$.

Chambeyron S, Bickmore WA. 2004. Chromatin decondensation and nuclear reorganization of the HoxB locus upon induction of transcription. Genes Dev 18: 11191130.

Chang KH, Fang X, Wang H, Huang A, Cao H, Yang Y, Bonig H, Stamatoyannopoulos JA, Papayannopoulou T. 2013. Epigenetic modifications and chromosome conformations of the $\beta$ globin locus throughout development. Stem Cell Rev 9: 397-407.

Chen H, Chen J, Muir LA, Ronquist S, Meixner W, Ljungman M, Ried T, Smale S, Rajapakse I. 2015. Functional organization of the human 4D nucleome. Proc Natl Acad Sci 112: 8002-8007.

Chiang CK, Mehta N, Patel A, Zhang P, Ning Z, Mayne J, Sun WY, Cheng HY, Figeys D. 2014. The proteomic landscape of the suprachiasmatic nucleus clock reveals large-scale coordination of key biological processes. PLoS Genet 10: e1004695.

Cho H, Zhao X, Hatori M, Yu RT, Barish GD, Lam MT, Chong LW, DiTacchio L, Atkins AR, Glass CK, et al. 2012. Regulation of circadian behaviour and metabolism by REV-ERB- $\alpha$ and REV-ERB- $\beta$. Nature 485: $123-127$.

Chow GC. 1960. Tests of equality between sets of coefficients in 2 linear regressions. Econometrica 28: 591-605.

Costa MJ, Finkenstadt B, Roche V, Levi F, Gould PD, Foreman J, Halliday K, Hall A, Rand DA. 2013. Inference on periodicity of circadian time series. Biostatistics 14: 792806.

Cremer T, Cremer C. 2001. Chromosome territories, nuclear architecture and gene regulation in mammalian cells Nat Rev Genet 2: 292-301.

Damiola F, Le Minh N, Preitner N, Kornmann B, FleuryOlela F, Schibler U. 2000. Restricted feeding uncouples circadian oscillators in peripheral tissues from the central pacemaker in the suprachiasmatic nucleus. Genes Dev 14: 2950-2961.

de Wit E, de Laat W. 2012. A decade of 3C technologies: Insights into nuclear organization. Genes Dev 26: 11-24.

Dekker J, Heard E. 2015. Structural and functional diversity of topologically associating domains. FEBS Lett 589: 2877-2884.

Dekker J, Rippe K, Dekker M, Kleckner N. 2002. Capturing chromosome conformation. Science 295: 1306-1311.

Deng W, Rupon JW, Krivega I, Breda L, Motta I, Jahn KS, Reik A, Gregory PD, Rivella S, Dean A, et al. 2014. Reactivation of developmentally silenced globin genes by forced chromatin looping. Cell 158: 849-860.

Dixon JR, Selvaraj S, Yue F, Kim A, Li Y, Shen Y, Hu M, Liu JS, Ren B. 2012. Topological domains in mammalian genomes identified by analysis of chromatin interactions. Nature 485: 376-380.

Doherty CJ, Kay SA. 2010. Circadian control of global gene expression patterns. Annu Rev Genet 44: 419-444.

Doi M, Hirayama J, Sassone-Corsi P. 2006. Circadian regulator CLOCK is a histone acetyltransferase. Cell 125: $497-$ 508.

Dostie J, Richmond TA, Arnaout RA, Selzer RR, Lee WL, Honan TA, Rubio ED, Krumm A, Lamb J, Nusbaum C, et al. 2006. Chromosome conformation capture carbon copy (5C): A massively parallel solution for mapping interactions between genomic elements. Genome Res 16: $1299-1309$. 
Du NH, Arpat AB, De Matos M, Gatfield D. 2014. MicroRNAs shape circadian hepatic gene expression on a transcriptome-wide scale. eLife 3: $\mathrm{e} 02510$.

Edgar RS, Green EW, Zhao Y, van Ooijen G, Olmedo M, Qin X, Xu Y, Pan M, Valekunja UK, Feeney KA, et al. 2012. Peroxiredoxins are conserved markers of circadian rhythms. Nature 485: 459-464.

Etchegaray JP, Lee C, Wade PA, Reppert SM. 2003. Rhythmic histone acetylation underlies transcription in the mammalian circadian clock. Nature 421: 177-182.

Etchegaray JP, Yang X, DeBruyne JP, Peters AH, Weaver DR, Jenuwein T, Reppert SM. 2006. The Polycomb group protein EZH2 is required for mammalian circadian clock function. J Biol Chem 281: 21209-21215.

Everett LJ, Lazar MA. 2014. Nuclear receptor Rev-erb $\alpha$ : Up, down, and all around. Trends Endocrinol Metab 25: 586592.

Fang B, Everett LJ, Jager J, Briggs E, Armour SM, Feng D, Roy A, Gerhart-Hines Z, Sun Z, Lazar MA. 2014. Circadian enhancers coordinate multiple phases of rhythmic gene transcription in vivo. Cell 159: 1140-1152.

Feng D, Liu T, Sun Z, Bugge A, Mullican SE, Alenghat T, Liu XS, Lazar MA. 2011. A circadian rhythm orchestrated by histone deacetylase 3 controls hepatic lipid metabolism. Science 331: 1315-1319.

Fisher RA. 1929. Tests of significance in harmonic analysis. Proc Roy Soc London A 125: 54-59.

Fonjallaz P, Ossipow V, Wanner G, Schibler U. 1996. The two PAR leucine zipper proteins, TEF and DBP, display similar circadian and tissue-specific expression, but have different target promoter preferences. EMBO J 15:351-362.

Fraser J, Williamson I, Bickmore WA, Dostie J. 2015. An overview of genome organization and how we got there: From FISH to Hi-C. Microbiol Mol Biol Rev 79: 347-372.

Fullwood MJ, Liu MH, Pan YF, Liu J, Xu H, Mohamed YB, Orlov YL, Velkov S, Ho A, Mei PH, et al. 2009. An oestrogen-receptor- $\alpha$-bound human chromatin interactome. Nature 462: 58-64.

Fustin JM, Doi M, Yamaguchi Y, Hida H, Nishimura S, Yoshida M, Isagawa T, Morioka MS, Kakeya H, Manabe I, et al. 2013. RNA-methylation-dependent RNA processing controls the speed of the circadian clock. Cell 155: 793-806.

Gachon F, Fonjallaz P, Damiola F, Gos P, Kodama T, Zakany J, Duboule D, Petit B, Tafti M, Schibler U. 2004. The loss of circadian PAR bZip transcription factors results in epilepsy. Genes Dev 18: 1397-1412.

Gachon F, Olela FF, Schaad O, Descombes P, Schibler U. 2006. The circadian PAR-domain basic leucine zipper transcription factors DBP, TEF, and HLF modulate basal and inducible xenobiotic detoxification. Cell Metab 4: $25-36$.

Gaidatzis D, Burger L, Florescu M, Stadler MB. 2015. Analysis of intronic and exonic reads in RNA-seq data characterizes transcriptional and post-transcriptional regulation. Nat Biotechnol 33: 722-729.

Gatfield D, Le Martelot G, Vejnar CE, Gerlach D, Schaad O, Fleury-Olela F, Ruskeepaa AL, Oresic M, Esau CC, Zdobnov EM, et al. 2009. Integration of microRNA miR-122 in hepatic circadian gene expression. Genes Dev 23: 13131326.
Gekakis N, Staknis D, Nguyen HB, Davis FC, Wilsbacher LD, King DP, Takahashi JS, Weitz CJ. 1998. Role of the CLOCK protein in the mammalian circadian mechanism. Science 280: 1564-1569.

Green CB, Douris N, Kojima S, Strayer CA, Fogerty J, Lourim D, Keller SR, Besharse JC. 2007. Loss of nocturnin, a circadian deadenylase, confers resistance to hepatic steatosis and diet-induced obesity. Proc Natl Acad Sci 104: $9888-9893$.

Guillaumond F, Dardente H, Giguere V, Cermakian N. 2005. Differential control of Bmall circadian transcription by REV-ERB and ROR nuclear receptors. J Biol Rhythms 20: 391-403.

Guo Y, Xu Q, Canzio D, Shou J, Li J, Gorkin DU, Jung I, Wu H, Zhai Y, Tang Y, et al. 2015. CRISPR inversion of CTCF sites alters genome topology and enhancer/promoter function. Cell 162: 900-910.

Hartley HO. 1949. Tests of significance in harmonic analysis. Biometrika 36: 194-201.

Hughes ME, DiTacchio L, Hayes KR, Vollmers C, Pulivarthy S, Baggs JE, Panda S, Hogenesch JB. 2009. Harmonics of circadian gene transcription in mammals. PLoS Genet 5: e1000442.

Hughes ME, Hogenesch JB, Kornacker K. 2010. JTK_CYCLE: An efficient nonparametric algorithm for detecting rhythmic components in genome-scale data sets. J Biol Rhythms 25: 372-380.

Hughes JR, Roberts N, McGowan S, Hay D, Giannoulatou E, Lynch M, De Gobbi M, Taylor S, Gibbons R, Higgs DR. 2014. Analysis of hundreds of cis-regulatory landscapes at high resolution in a single, high-throughput experiment. Nat Genet 46: 205-212.

Hughey JJ, Hastie T, Butte AJ. 2016. ZeitZeiger: Supervised learning for high-dimensional data from an oscillatory system. Nucleic Acids Res 5: e80.

Hussain MM, Pan X. 2015. Circadian regulation of macronutrient absorption. J Biol Rhythms 30: 459-469.

Jang C, Lahens NF, Hogenesch JB, Sehgal A. 2015. Ribosome profiling reveals an important role for translational control in circadian gene expression. Genome Res 25: 18361847.

Janich P, Arpat AB, Castelo-Szekely V, Lopes M, Gatfield D. 2015. Ribosome profiling reveals the rhythmic liver translatome and circadian clock regulation by upstream open reading frames. Genome Res 25: 1848-1859.

Jouffe C, Cretenet G, Symul L, Martin E, Atger F, Naef F, Gachon F. 2013. The circadian clock coordinates ribosome biogenesis. PLoS Biol 11: e1001455.

Katada S, Sassone-Corsi P. 2010. The histone methyltransferase MLL1 permits the oscillation of circadian gene expression. Nat Struct Mol Biol 17: 1414-1421.

Kim DY, Woo KC, Lee KH, Kim TD, Kim KT. 2010. hnRNP $\mathrm{Q}$ and PTB modulate the circadian oscillation of mouse Rev-erb $\alpha$ via IRES-mediated translation. Nucleic Acids Res 38: 7068-7078.

Kim JY, Kwak PB, Weitz CJ. 2014. Specificity in circadian clock feedback from targeted reconstitution of the NuRD corepressor. Mol Cell 56: 738-748.

Kind J, Pagie L, de Vries SS, Nahidiazar L, Dey SS, Bienko M, Zhan Y, Lajoie B, de Graaf CA, Amendola M, et al. 2015. 
J. Mermet et al.

Genome-wide maps of nuclear lamina interactions in single human cells. Cell 163: 134-147.

Koike N, Yoo SH, Huang HC, Kumar V, Lee C, Kim TK, Takahashi JS. 2012. Transcriptional architecture and chromatin landscape of the core circadian clock in mammals. Science 338: 349-354.

Kojima S, Matsumoto K, Hirose M, Shimada M, Nagano M, Shigeyoshi Y, Hoshino S, Ui-Tei K, Saigo K, Green CB, et al. 2007. LARK activates posttranscriptional expression of an essential mammalian clock protein, PERIOD1. Proc Natl Acad Sci 104: 1859-1864.

Kojima S, Gatfield D, Esau CC, Green CB. 2010. MicroRNA122 modulates the rhythmic expression profile of the circadian deadenylase Nocturnin in mouse liver. PLoS ONE 5: e11264.

Kojima S, Shingle DL, Green CB. 2011. Post-transcriptional control of circadian rhythms. J Cell Sci 124: 311-320.

Kojima S, Sher-Chen EL, Green CB. 2012. Circadian control of mRNA polyadenylation dynamics regulates rhythmic protein expression. Genes Dev 26: 2724-2736.

Kojima S, Gendreau KL, Sher-Chen EL, Gao P, Green CB. 2015. Changes in poly(A) tail length dynamics from the loss of the circadian deadenylase nocturnin. Sci Rep 5: 17059.

Korencic A, Kosir R, Bordyugov G, Lehmann R, Rozman D, Herzel H. 2014. Timing of circadian genes in mammalian tissues. Sci Rep 4: 5782.

Kornmann B, Schaad O, Bujard H, Takahashi JS, Schibler U. 2007. System-driven and oscillator-dependent circadian transcription in mice with a conditionally active liver clock. PLoS Biol 5: e34.

Kume K, Zylka MJ, Sriram S, Shearman LP, Weaver DR, Jin X, Maywood ES, Hastings MH, Reppert SM. 1999. mCRY1 and mCRY2 are essential components of the negative limb of the circadian clock feedback loop. Cell 98: 193-205.

Lee KH, Woo KC, Kim DY, Kim TD, Shin J, Park SM, Jang SK, Kim KT. 2012. Rhythmic interaction between Period 1 mRNA and hnRNP Q leads to circadian time-dependent translation. Mol Cell Biol 32: 717-728.

Le Martelot G, Canella D, Symul L, Migliavacca E, Gilardi F, Liechti R, Martin O, Harshman K, Delorenzi M, Desvergne B, et al. 2012. Genome-wide RNA polymerase II profiles and RNA accumulation reveal kinetics of transcription and associated epigenetic changes during diurnal cycles. PLoS Biol 10: e1001442.

Leng N, Chu LF, Barry C, Li Y, Choi J, Li X, Jiang P, Stewart RM, Thomson JA, Kendziorski C. 2015. Oscope identifies oscillatory genes in unsynchronized single-cell RNAseq experiments. Nat Methods 12: 947-950.

Li R, Yue J, Zhang Y, Zhou L, Hao W, Yuan J, Qiang B, Ding JM, Peng X, Cao JM. 2008. CLOCK/BMAL1 regulates human nocturnin transcription through binding to the E-box of nocturnin promoter. Mol Cell Biochem 317: 169-177.

Lian X, Guo J, Gu W, Cui Y, Zhong J, Jin J, He QY, Wang T, Zhang G. 2016. Genome-wide and experimental resolution of relative translation elongation speed at individual gene level in human cells. PLoS Genet 12: e1005901.

Lieberman-Aiden E, van Berkum NL, Williams L, Imakaev M, Ragoczy T, Telling A, Amit I, Lajoie BR, Sabo PJ,
Dorschner MO, et al. 2009. Comprehensive mapping of long-range interactions reveals folding principles of the human genome. Science 326: 289-293.

Lipton JO, Yuan ED, Boyle LM, Ebrahimi-Fakhari D, Kwiatkowski E, Nathan A, Guttler T, Davis F, Asara JM, Sahin M. 2015. The circadian protein BMAL1 regulates translation in response to S6K1-mediated phosphorylation. Cell 161: 1138-1151.

Liu Y, Hu W, Murakawa Y, Yin J, Wang G, Landthaler M, Yan J. 2013. Cold-induced RNA-binding proteins regulate circadian gene expression by controlling alternative polyadenylation. Sci Rep 3: 2054.

Love MI, Huber W, Anders S. 2014. Moderated estimation of fold change and dispersion for RNA-seq data with DESeq2. Genome Biol 15: 550.

Luck S, Westermark PO. 2016. Circadian mRNA expression: Insights from modeling and transcriptomics. Cell $\mathrm{Mol}$ Life Sci 73: 497-521.

Luck S, Thurley K, Thaben PF, Westermark PO. 2014. Rhythmic degradation explains and unifies circadian transcriptome and proteome data. Cell Rep 9: 741-751.

Mauvoisin D, Wang J, Jouffe C, Martin E, Atger F, Waridel P, Quadroni M, Gachon F, Naef F. 2014. Circadian clockdependent and -independent rhythmic proteomes implement distinct diurnal functions in mouse liver. Proc Natl Acad Sci 111: 167-172.

McGlincy NJ, Valomon A, Chesham JE, Maywood ES, Hastings MH, Ule J. 2012. Regulation of alternative splicing by the circadian clock and food related cues. Genome Biol 13: R54.

Mehra A, Baker CL, Loros JJ, Dunlap JC. 2009. Post-translational modifications in circadian rhythms. Trends Biochem Sci 34: 483-490.

Menet JS, Rodriguez J, Abruzzi KC, Rosbash M. 2012. Nascent-Seq reveals novel features of mouse circadian transcriptional regulation. eLife 1: e00011.

Menet JS, Pescatore S, Rosbash M. 2014. CLOCK:BMAL1 is a pioneer-like transcription factor. Genes Dev 28: 8-13.

Mifsud B, Tavares-Cadete F, Young AN, Sugar R, Schoenfelder S, Ferreira L, Wingett SW, Andrews S, Grey W, Ewels PA, et al. 2015. Mapping long-range promoter contacts in human cells with high-resolution capture $\mathrm{Hi}-\mathrm{C}$ Nature Genet 47: 598-606.

Mohawk JA, Takahashi JS. 2011. Cell autonomy and synchrony of suprachiasmatic nucleus circadian oscillators. Trends Neurosci 34: 349-358.

Mohawk JA, Green CB, Takahashi JS. 2012. Central and peripheral circadian clocks in mammals. Annu Rev Neurosci 35: 445-462.

Morf J, Rey G, Schneider K, Stratmann M, Fujita J, Naef F, Schibler U. 2012. Cold-inducible RNA-binding protein modulates circadian gene expression posttranscriptionally. Science 338: 379-383.

Nagano T, Lubling Y, Stevens TJ, Schoenfelder S, Yaffe E, Dean W, Laue ED, Tanay A, Fraser P. 2013. Single-cell $\mathrm{Hi}-\mathrm{C}$ reveals cell-to-cell variability in chromosome structure. Nature 502: 59-64.

Nagoshi E, Saini C, Bauer C, Laroche T, Naef F, Schibler U. 2004. Circadian gene expression in individual fibroblasts: Cell-autonomous and self-sustained oscillators pass time to daughter cells. Cell 119: 693-705. 
Nakahata Y, Kaluzova M, Grimaldi B, Sahar S, Hirayama J, Chen D, Guarente LP, Sassone-Corsi P. 2008. The NAD ${ }^{+}$. dependent deacetylase SIRT1 modulates CLOCK-mediated chromatin remodeling and circadian control. Cell 134: $329-340$

Narumi R, Shimizu Y, Ukai-Tadenuma M, Ode KL, Kanda GN, Shinohara Y, Sato A, Matsumoto K, Ueda HR. 2016. Mass spectrometry-based absolute quantification reveals rhythmic variation of mouse circadian clock proteins. Proc Natl Acad Sci 113: E3461-E34617.

Neufeld-Cohen A, Robles MS, Aviram R, Manella G, Adamovich Y, Ladeuix B, Nir D, Rousso-Noori L, Kuperman Y, Golik M, et al. 2016. Circadian control of oscillations in mitochondrial rate-limiting enzymes and nutrient utilization by PERIOD proteins. Proc Natl Acad Sci 113: E1673-E1682.

Nilsen TW, Graveley BR. 2010. Expansion of the eukaryotic proteome by alternative splicing. Nature 463: 457-463.

Noble WS. 2009. How does multiple testing correction work? Nat Biotechnol 27: 1135-1137.

Noordermeer D, Leleu M, Splinter E, Rougemont J, De Laat W, Duboule D. 2011. The dynamic architecture of Hox gene clusters. Science 334: 222-225.

Noordermeer D, Leleu M, Schorderet P, Joye E, Chabaud F, Duboule D. 2014. Temporal dynamics and developmental memory of 3D chromatin architecture at Hox gene loci. eLife 3: $\mathrm{e} 02557$.

Panda S, Antoch MP, Miller BH, Su AI, Schook AB, Straume M, Schultz PG, Kay SA, Takahashi JS, Hogenesch JB. 2002. Coordinated transcription of key pathways in the mouse by the circadian clock. Cell 109: 307-320.

Partch CL, Green CB, Takahashi JS. 2014. Molecular architecture of the mammalian circadian clock. Trends Cell Biol 24: 90-99.

Podobed P, Pyle WG, Ackloo S, Alibhai FJ, Tsimakouridze EV, Ratcliffe WF, Mackay A, Simpson J, Wright DC, Kirby GM, et al. 2014. The day/night proteome in the murine heart. Am J Physiol Regul Integr Comp Physiol 307: R121137.

Preitner N, Damiola F, Lopez-Molina L, Zakany J, Duboule D, Albrecht U, Schibler U. 2002. The orphan nuclear receptor REV-ERB $\alpha$ controls circadian transcription within the positive limb of the mammalian circadian oscillator. Cell 110: 251-260.

Preussner M, Wilhelmi I, Schultz AS, Finkernagel F, Michel M, Moroy T, Heyd F. 2014. Rhythmic U2af26 alternative splicing controls PERIOD1 stability and the circadian clock in mice. Mol Cell 54: 651-662.

Ramsey KM, Yoshino J, Brace CS, Abrassart D, Kobayashi Y, Marcheva B, Hong HK, Chong JL, Buhr ED, Lee C, et al. 2009. Circadian clock feedback cycle through NAMPTmediated NAD ${ }^{+}$biosynthesis. Science 324: 651-654.

Rao SS, Huntley MH, Durand NC, Stamenova EK, Bochkov ID, Robinson JT, Sanborn AL, Machol I, Omer AD, Lander ES, et al. 2014. A 3D map of the human genome at kilobase resolution reveals principles of chromatin looping. Cell 159: 1665-1680.

Reddy AB, Karp NA, Maywood ES, Sage EA, Deery M, O’Neill JS, Wong GK, Chesham J, Odell M, Lilley KS, et al. 2006. Circadian orchestration of the hepatic proteome. Curr Biol 16: 1107-1115.
Rey G, Cesbron F, Rougemont J, Reinke H, Brunner M, Naef F. 2011. Genome-wide and phase-specific DNA-binding rhythms of BMAL1 control circadian output functions in mouse liver. PLoS Biol9: e1000595.

Ripperger JA, Schibler U. 2006. Rhythmic CLOCK-BMAL1 binding to multiple E-box motifs drives circadian Dbp transcription and chromatin transitions. Nat Genet 38: 369-374.

Robinson I, Reddy AB. 2014. Molecular mechanisms of the circadian clockwork in mammals. FEBS Lett 588: 2477 2483.

Robinson BG, Frim DM, Schwartz WJ, Majzoub JA. 1988. Vasopressin mRNA in the suprachiasmatic nuclei: Daily regulation of polyadenylate tail length. Science 241: $342-$ 344.

Robles MS, Cox J, Mann M. 2014. In-vivo quantitative proteomics reveals a key contribution of post-transcriptional mechanisms to the circadian regulation of liver metabolism. PLoS Genet 10: e1004047.

Sangoram AM, Saez L, Antoch MP, Gekakis N, Staknis D, Whiteley A, Fruechte EM, Vitaterna MH, Shimomura K, King DP, et al. 1998. Mammalian circadian autoregulatory loop: A timeless ortholog and mPer1 interact and negatively regulate CLOCK-BMAL1-induced transcription. Neuron 21: 1101-1113.

Schoenfelder S, Furlan-Magaril M, Mifsud B, Tavares-Cadete F, Sugar R, Javierre BM, Nagano T, Katsman Y Sakthidevi M, Wingett SW, et al. 2015. The pluripotent regulatory circuitry connecting promoters to their longrange interacting elements. Genome Res 25: 582-597.

Seitan VC, Faure AJ, Zhan Y, McCord RP, Lajoie BR, IngSimmons E, Lenhard B, Giorgetti L, Heard E, Fisher AG, et al. 2013. Cohesin-based chromatin interactions enable regulated gene expression within preexisting architectural compartments. Genome Res 23: 2066-2077.

Simonis M, Klous P, Splinter E, Moshkin Y, Willemsen R, de Wit E, van Steensel B, de Laat W. 2006. Nuclear organization of active and inactive chromatin domains uncovered by chromosome conformation capture-on-chip (4C). Nat Genet 38: 1348-1354.

Stokkan KA, Yamazaki S, Tei H, Sakaki Y, Menaker M. 2001. Entrainment of the circadian clock in the liver by feeding. Science 291: 490-493.

Storch KF, Lipan O, Leykin I, Viswanathan N, Davis FC, Wong WH, Weitz CJ. 2002. Extensive and divergent circadian gene expression in liver and heart. Nature 417: $78-83$.

Stratmann M, Suter DM, Molina N, Naef F, Schibler U. 2012 Circadian Dbp transcription relies on highly dynamic BMAL1-CLOCK interaction with $\mathrm{E}$ boxes and requires the proteasome. Mol Cell 48: 277-287.

Suter DM, Molina N, Gatfield D, Schneider K, Schibler U, Naef F. 2011. Mammalian genes are transcribed with widely different bursting kinetics. Science 332: 472474.

Takeda Y, Jothi R, Birault V, Jetten AM. 2012. RORgamma directly regulates the circadian expression of clock genes and downstream targets in vivo. Nucleic Acids Res 40: 8519-8535.

Thaben PF, Westermark PO. 2014. Detecting rhythms in time series with RAIN. J Biol Rhythms 29: 391-400. 
J. Mermet et al.

Tolhuis B, Palstra RJ, Splinter E, Grosveld F, de Laat W. 2002. Looping and interaction between hypersensitive sites in the active $\beta$-globin locus. Mol Cell 10: 14531465.

Tsujimura T, Klein FA, Langenfeld K, Glaser J, Huber W, Spitz F. 2015. A discrete transition zone organizes the topological and regulatory autonomy of the adjacent Tfap2c and Bmp7 genes. PLoS Genet 11: e1004897.

Valekunja UK, Edgar RS, Oklejewicz M, van der Horst GT, O’Neill JS, Tamanini F, Turner DJ, Reddy AB. 2013. Histone methyltransferase MLL3 contributes to genomescale circadian transcription. Proc Natl Acad Sci 110: 1554-1559.

Vanselow K, Vanselow JT, Westermark PO, Reischl S, Maier B, Korte T, Herrmann A, Herzel H, Schlosser A, Kramer A. 2006. Differential effects of PER2 phosphorylation: Molecular basis for the human familial advanced sleep phase syndrome (FASPS). Genes Dev 20: 2660-2672.

Vietri Rudan M, Barrington C, Henderson S, Ernst C, Odom DT, Tanay A, Hadjur S. 2015. Comparative Hi-C reveals that CTCF underlies evolution of chromosomal domain architecture. Cell Rep 10: 1297-1309.

Vollmers C, Gill S, DiTacchio L, Pulivarthy SR, Le HD, Panda S. 2009. Time of feeding and the intrinsic circadian clock drive rhythms in hepatic gene expression. Proc Natl Acad Sci 106: 21453-21458.

Welsh DK, Yoo SH, Liu AC, Takahashi JS, Kay SA. 2004 Bioluminescence imaging of individual fibroblasts reveals persistent, independently phased circadian rhythms of clock gene expression. Curr Biol 14: 2289-2295.

Wijnen H, Naef F, Young MW. 2005. Molecular and statistical tools for circadian transcript profiling. Methods Enzymol 393: 341-365.

Xu Y, Guo W, Li P, Zhang Y, Zhao M, Fan Z, Zhao Z, Yan J. 2016. Long-range chromosome interactions mediated by cohesin shape circadian gene expression. PLoS Genet 12: e1005992.

Yin L, Lazar MA. 2005. The orphan nuclear receptor Reverb $\alpha$ recruits the $\mathrm{N}-\mathrm{CoR} /$ histone deacetylase 3 corepressor to regulate the circadian Bmall gene. Mol Endocrinol 19: $1452-1459$.

Zhang R, Lahens NF, Ballance HI, Hughes ME, Hogenesch JB. 2014. A circadian gene expression atlas in mammals: implications for biology and medicine. Proc Natl Acad Sci 111: 16219-16224.

Zhang Y, Fang B, Emmett MJ, Damle M, Sun Z, Feng D, Armour SM, Remsberg JR, Jager J, Soccio RE, et al. 2015. GENE REGULATION. Discrete functions of nuclear receptor Rev-erb $\alpha$ couple metabolism to the clock. Science 348: $1488-1492$.

Zhao H, Sifakis EG, Sumida N, Millan-Arino L, Scholz BA, Svensson JP, Chen X, Ronnegren AL, Mallet de Lima CD, Varnoosfaderani FS, et al. 2015. PARP1- and CTCF-mediated interactions between active and repressed chromatin at the lamina promote oscillating transcription. Mol Cell 59: 984-997.

Zheng B, Larkin DW, Albrecht U, Sun ZS, Sage M, Eichele G, Lee CC, Bradley A. 1999. The mPer2 gene encodes a functional component of the mammalian circadian clock. Nature 400: 169-173.

Zhou M, Kim JK, Eng GW, Forger DB, Virshup DM. 2015. A Period2 phosphoswitch regulates and temperature compensates circadian period. Mol Cell 60: 77-88.

Zuin J, Dixon JR, van der Reijden MI, Ye Z, Kolovos P, Brouwer RW, van de Corput MP, van de Werken HJ, Knoch TA, van IWF, et al. 2014. Cohesin and CTCF differentially affect chromatin architecture and gene expression in human cells. Proc Natl Acad Sci 111: 9961001. 


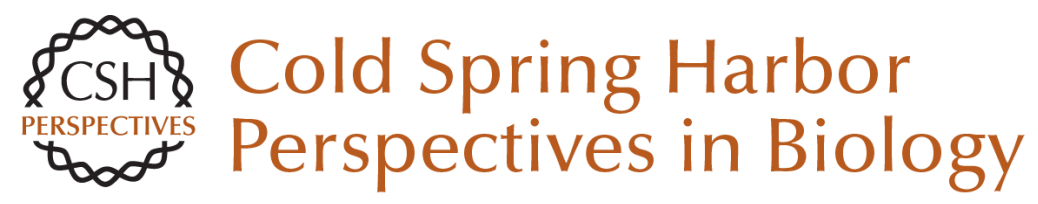

\title{
Systems Chronobiology: Global Analysis of Gene Regulation in a 24-Hour Periodic World
}

\author{
Jérôme Mermet, Jake Yeung and Felix Naef
}

Cold Spring Harb Perspect Biol 2017; doi: 10.1101/cshperspect.a028720 originally published online December 5, 2016

\section{Subject Collection Circadian Rhythms}

\section{Circadian Posttranscriptional Regulatory \\ Mechanisms in Mammals \\ Carla B. Green}

Design Principles of Phosphorylation-Dependent

Timekeeping in Eukaryotic Circadian Clocks

Koji L. Ode and Hiroki R. Ueda

Interplay between Microbes and the Circadian

Clock

Paola Tognini, Mari Murakami and Paolo Sassone-Corsi

A 50-Year Personal Journey: Location, Gene

Expression, and Circadian Rhythms Michael Rosbash

Regulating the Suprachiasmatic Nucleus (SCN)

Circadian Clockwork: Interplay between

Cell-Autonomous and Circuit-Level Mechanisms Erik D. Herzog, Tracey Hermanstyne, Nicola J. Smyllie, et al.

Systems Chronobiology: Global Analysis of Gene Regulation in a 24-Hour Periodic World Jérôme Mermet, Jake Yeung and Felix Naef

\author{
Coordination between Differentially Regulated \\ Circadian Clocks Generates Rhythmic Behavior \\ Deniz Top and Michael W. Young \\ Introduction to Chronobiology \\ Sandra J. Kuhlman, L. Michon Craig and Jeanne F. \\ Duffy \\ Cellular Timekeeping: It's Redox o'Clock \\ Nikolay B. Milev, Sue-Goo Rhee and Akhilesh B. \\ Reddy
}

Molecular Mechanisms of Sleep Homeostasis in Flies and Mammals

Ravi Allada, Chiara Cirelli and Amita Sehgal

Membrane Currents, Gene Expression, and

Circadian Clocks

Charles N. Allen, Michael N. Nitabach and Christopher S. Colwell

The Plant Circadian Clock: From a Simple Timekeeper to a Complex Developmental Manager Sabrina E. Sanchez and Steve A. Kay

For additional articles in this collection, see http://cshperspectives.cshlp.org/cgi/collection/

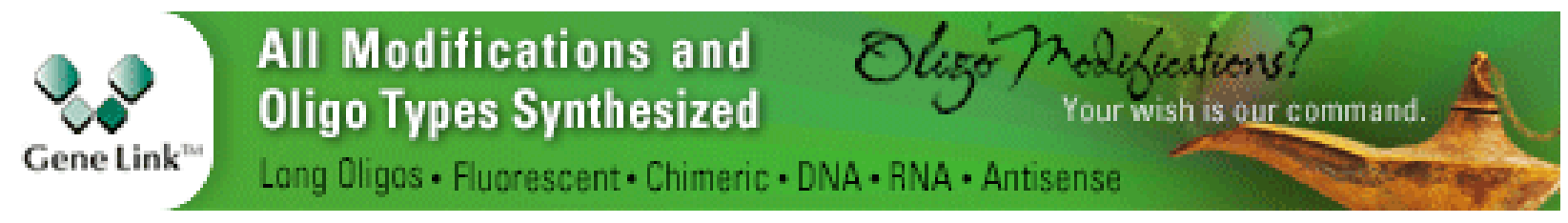

